\title{
Sociología del Arte Apuntes historiográficos entre Hauser y Francastel
}

\author{
Sociology of Art \\ Historiographical Notes between Hauser and Francastel
}

\author{
María Inés Gannon \\ mariainesgannon@gmail.com \\ Facultad de Bellas Artes. Universidad \\ Nacional de La Plata. Argentina \\ Recibido: 6/11/2018 \\ Aceptado: 28/3/2019
}

\begin{abstract}
Resumen
El presente trabajo tiene como objetivo confrontar y analizar, desde un punto de vista historiográfico, las diferentes visiones y concepciones de los historiadores del arte Arnold Hauser y Pierre Francastel. Para la selección particular de estos autores se ha tomado en cuenta que Hauser es considerado el padre de la Sociología del Arte y produjo uno de los primeros estudios enmarcados dentro de esta asignatura. Como contrapartida, se analizarán los estudios realizados por Francastel debido a que el autor genera críticas y aportes significativos a aquella primera concepción de la Sociología del Arte.
\end{abstract}

\section{Palabras clave}

Sociología; arte; Hauser; Francastel; historiografía

\begin{abstract}
The aim of the present work is to compare and analyse, from a historiographical perspective, the different ideas and views of the art historians Arnold Hauser and Pierre Francastel. For the particular selection of these authors, it has been taken into account that Hauser is considered the father of Sociology of Art and made one of the first studies framed within this subject. In exchange, the studies carried out by Francastel will be analysed due to the fact that the author wrote criticisms and significant contributions to that first conception of Sociology of Art.
\end{abstract}

\section{Keywords}

Sociology; Art; Hauser; Francastel; Historiography 


\section{AVANCES

El historiador del arte Arnold Hauser (1892-1978) junto con Frederick Antal (1887-1954) son considerados los pioneros de la Sociología del Arte, disciplina teórica que se aboca al análisis de las producciones artísticas. La misma entiende a su objeto de estudio como el resultado de la sociedad y afirma que estas creaciones se encuentran atravesadas por los diversos componentes que conforman dicha sociedad. A mediados del siglo XX surgen dos escritos que constituyen los pilares de esta nueva disciplina: La pintura florentina y su ambiente social (1948) de Antal, e Historia social de la literatura y el arte (1951), de Hauser.

Hauser centró sus estudios en los modos de producción del arte, dejando de lado el análisis formal de las obras artísticas. El autor concibió al arte como el resultado de una relación compleja entre lo social, lo económico y lo político. Asimismo, no consideraba que una obra artística se encontraba únicamente influenciada por estos factores, sino que percibía las producciones como un reflejo de las estructuras sociales contemporáneas al momento de su realización.

El historiador se vio influenciado por las teorías provenientes de la corriente marxista, de donde partió para tomar un posicionamiento concreto en lo que respecta a la sociología, la historia, la economía y la cultura. El autor formó parte de la escuela de pensamiento sobre historia del arte de la Universidad de Viena, denominada la Escuela de Viena, que contaba con Heinrich Wölfflin, Alois Riegl y György Lukács entre sus principales referentes. La ideología marxista influyó fuertemente en los escritos de Hauser y atravesó todas sus líneas de análisis, es por eso que el autor estudiaba y comprendía al arte como un elemento inseparable de su contexto histórico y social, en estrecha relación con aquellos fenómenos que conforman la sociedad en sí misma: la economía, las clases sociales, etcétera.

En el texto inaugural de esta nueva disciplina teórica, Historia social de la literatura y el arte, el autor realizó una reseña que abarca la historia del arte occidental, presentando a las producciones artísticas en un orden cronológico a lo largo de la historia. En este escrito, Hauser propuso un análisis sin describir particularmente ningún objeto o pieza estética, sino que, más bien, hizo un enfoque en los factores socioeconómicos y políticos de las diversas épocas que estudiaba, cristalizando así su perspectiva teórica marxista a la hora de abordar los estudios culturales y artísticos. El historiador utiliza esta metodología no solamente para el estudio de las etapas prehistóricas, sino también para el de todos los períodos consiguientes. Este recurso guarda relación con una intención política de entender el mundo haciendo hincapié en los factores que conforman el conjunto de la sociedad. 
Estos lineamientos característicos de los estudios realizados por Hauser se evidencian sobre todo en sus primeros escritos $y$, por lo tanto, han generado múltiples críticas por parte de historiadores posteriores. Un señalamiento particular ha sido catalogarlo como un impulsor del marxismo vulgar, es decir, criticarlo por condensar sus estudios en un mero reduccionismo económico y social aplicado a las producciones artísticas de una época determinada. En ese sentido, uno de sus principales críticos fue el historiador del arte Ernst Gombrich (1909-2001), cuyo texto La historia del arte (1950) fue contemporáneo al estudio inaugural de Hauser. Gombrich consideró que los estudios sociológicos de su par de origen húngaro se reducían a un determinismo social. Asimismo, lo criticó por seleccionar únicamente aquellos materiales que consideró más significativos de una época, como también por juzgar que si una forma artística no encajaba en su esquema fuera considerada como una contradicción entre la estructura y la infraestructura (Gombrich, 1963).

Arnold Hauser aplicó este método reduccionista no solamente al estudio de las obras artísticas, sino también a la observación del productor y del público que las consume, componentes constitutivos del estudio de la Sociología del Arte. Con respecto a la figura del artista, la consideraba como el vehículo que materializa los intereses y las tendencias de una época y de una clase social determinada. De este modo, el autor no concebía al autor de la obra como una figura aislada de su contexto histórico-social sino como un actor comprometido íntegramente con su entorno. Asimismo, en lo que respecta al estudio del público consumidor, también consideraba que sus gustos estéticos se encuentran condicionados por la pertenencia de clase.

Hauser perteneció a la primera corriente abocada a la Sociología del Arte, fundada a partir de las mencionadas premisas y supuestos que conformaron la nueva disciplina. Posteriormente, el historiador y crítico de arte francés Pierre Francastel, adepto a la Sociología del Arte, realizó ciertas apreciaciones y adiciones a esta corriente. Sus principales textos son: Arte y sociología (1948), Pintura y Sociedad (1951) y Sociología del arte (1970).

Francastel rebatió los estudios llevados a cabo por Hauser, debido a que consideraba que el historiador marxista generaba análisis superficiales del contexto histórico de las obras de arte, sin ahondar en ellas. En ese sentido, el autor propuso un nuevo enfoque en la Sociología del Arte, orientado a los objetos. Es decir, sostuvo que el basamento fundamental de esta disciplina consistía en el análisis exhaustivo de las obras de arte, en contraposición a los escritos de Hauser que, según el historiador francés, no tenían en cuenta al objeto artístico en sí mismo. De esta manera, Francastel 


\section{AVANCES

DE

propuso una sociología basada en el análisis de la obra y, por consiguiente, una metodología que preste mayor atención al análisis del campo visual. En esta línea de pensamiento, el autor planteó el concepto de destrucción del espacio plástico del Romanticismo al Impresionismo.

Esto no quiere decir que el autor no le otorgue trascendencia al contexto histórico de las producciones artísticas. No obstante, hace hincapié en que no debe abordarse al objeto como un mero dato de creación, sino que debe ser considerado como un producto de una actividad problemática, cuyas posibilidades técnicas y sus valores abstractos varían de acuerdo al ámbito en que se enmarque.

Otro aporte realizado por Francastel es la importancia que le otorga a la figura del artista, fundamentalmente, porque sin su dedicación, producción y técnica la obra de arte no existiría. Esta valoración del artista está intrínsecamente relacionada con su visión de la obra de arte, a la que no concibe como un reflejo de la sociedad, como proponía Hauser. Si bien el objeto artístico logra expresar los valores de su época es el artista quien, junto a su producción, contribuye también a crear y a colaborar con esa realidad en la que se encuentra inmerso.

Para finalizar con los aportes propuestos por Francastel es pertinente destacar que para el autor uno de los fines de la Sociología del Arte como disciplina científica supone atribuir el mismo grado de importancia a las obras de arte del pasado, más alejadas de la contemporaneidad, que a las obras presentes y cercanas. Esto se debe a que gracias a las obras más antiguas es posible recuperar y conocer aspectos significativos de las civilizaciones. El autor propone un análisis a partir de dos perspectivas: una, que analice la cultura y el contexto general de un período determinado; y otra, que abarque la capacidad artística del productor de la obra. Según Francastel, estos aspectos son fundamentales para el inicio de un análisis posicionado desde la Sociología del Arte que propone.

Como conclusión es importante resaltar que si bien ambos autores se enmarcan en la misma corriente historiográfica, denominada Sociología del Arte, y realizan aportes significativos en el campo de la Historia del Arte, presentan divergencias en sus investigaciones. Arnold Hauser, el iniciador de esta nueva metodología, influenciado por el pensamiento marxista se encarga de analizar la obra de arte como un producto de la sociedad, por lo que será necesario comprender el contexto histórico-social, político y económico para completar el estudio integral de una pieza artística.

Por su parte, Pierre Francastel, si bien toma como punto de partida esta nueva corriente sociológica para analizar el arte, presenta ciertas discrepancias y propone tomar en cuenta otros 
aspectos. Sugiere que la investigación en Sociología del Arte debe tener como eje central al objeto, es decir, focalizar el análisis en la pieza artística - a diferencia de Hauser, que no realizaba un análisis exhaustivo de la misma-. Aunque no le resta importancia a la cultura en la cual la obra se encuentra inmersa, renuncia al concepto de la obra de arte como reflejo de una realidad específica debido a que considera que el artista en su producción no solo expresa los valores de una época, sino que también contribuye a construirlos.

En este breve recorrido, la intención fue poner de manifiesto las ideas de ambos autores y cómo contribuyeron significativamente a la Historia del Arte, tanto al proponer una nueva metodología para la investigación de las obras de arte, como al sumar aportes y colaboraciones para enriquecer la disciplina.

\section{Referencias}

Antal, F. [1948] (1989). La pintura florentina y su ambiente social. Madrid, España: Alianza.

Francastel, P. [1948] (1965). Arte y sociología. En La realidad figurativa: elementos estructurales de la sociología del arte (pp. 27-55). París, Francia: Denoël/Gonthier.

Francastel, P. [1951] (1990). Pintura y sociedad. Madrid, España: Cátedra.

Francastel, P. [1970] (1984). Sociología del arte. Buenos Aires, Argentina: Alianza-Emecé.

Gombrich, E. [1950] (2009). La historia del arte. Londres, Inglaterra: Phaidon.

Gombrich, E. (1963). Meditaciones sobre un caballo de juguete. Madrid, España: Debate.

Hauser, A. (1951). Historia social de la literatura y el arte. Madrid, España: Guadarrama. 